\title{
Kırgızistan GSM Sektöründe Hizmet Pazarlaması ve Hizmet Kalitesi Uygulamalarının Değerlendirilmesi ${ }^{1}$
}

\author{
Azamat MAKSÜDÜNOV ${ }^{2}$
}

Öz

Hizmet sektörü birçok ülkede önde gelen bir sektör olmakla birlikte, sektörün yönetimi ile ilgili teorik altyapının da devamlı yeni araştırmalarla desteklenerek geliştirilmekte olduğu görülmektedir. Bilindiği gibi dünya genelinde rekabet koşulları her geçen gün daha şiddetli bir şekilde artmakta ve bu şartlar altında işletmelerin uzun dönemli başarılarını sağlayacak temel unsurlar içerisinde kalite ve pazarlama anlayışı da yer almaktadır. Bu çalışmanın temel amacı Kırgızistan'ın GSM sektöründe hizmet pazarlaması ve kalite uygulamalarının genel bir değerlendirmesini yapmaktır. Bu doğrultuda, öncelikle hizmet pazarlaması alanındaki teorik modeller incelenmiş ve hizmet kalitesiyle ilişkisi ortaya konulmaya çalışılmıştır. Daha sonra, Kırgızistan'ın GSM sektöründeki uygulamalar pazarlama karması bileşenleri açısından değerlendirilmiştir. Değerlendirme sonuçlarına göre, hizmet kalitesinin müşterilerin bekledikleri ve algıladıkları pazarlama performansına bağlı olduğu, bu çerçevede Kırgızistan GSM sektörünün henüz müşteri odaklı pazarlama anlayışını benimsemediği ve pazarlama karmasına bütünleşik bir yaklaşımın sergilenmediği belirlenmiştir. Araştırmanın sonuçlarının GSM sektöründe faaliyet gösteren işletmeler, bu işletmelerin faaliyetlerini düzenleyen devlet kurumları ve bu alanda araştırma yapacak olan tüm taraflar için yararlı olacağı düşünülmektedir.

Anabtar Kelimeler: Pazarlama karması, Hizmet kalitesi, GSM sektörü, Kırg1zistan

\section{Evaluation of Service Marketing and Service Quality Practices in Kyrgyzstan GSM Sector}

\begin{abstract}
Academic studies show that service industry is the leading sector in many economies and the theoretical basis on management of the industry is constantly being developed and supported by new researches. As known, market competitive conditions around the globe are increasing day by day, and under these conditions, quality and marketing are appearing as the main variables that will ensure the long-term success of any business. Therefore, main purpose of this study is to make a general evaluation of service marketing and quality practices in the GSM sector of Kyrgyzstan. In this context, first of all, theoretical models in the field of service marketing were examined and their relationship with service quality was revealed. Afterwards, the applications in the GSM sector of Kyrgyzstan are evaluated in terms of marketing mix components. According to the results, it has been revealed that the service quality depends on the expected and perceived marketing performance, within this framework, GSM sector in Kyrgyzstan has not yet adopted a customer-oriented marketing approach and is not in an integrated approach to the marketing mix. Results of the study would be useful for operating companies in GSM sector, related governmental institutions and also for future researches on this topic.
\end{abstract}

Key Words: Marketing mix, Service quality, GSM sector, Kyrgyzstan

\section{Atıf İçin / Please Cite As:}

Maksüdünov, A. (2022). Kırgızistan GSM sektöründe hizmet pazarlaması ve hizmet kalitesi uygulamalarının değerlendirilmesi. Manas Sosyal Arastırmalar Dergisi, 11(1), 458-469.

\footnotetext{
${ }^{1}$ Bu makale Azamat Maksüdünov'un Prof. Dr. Kasım Karahan'ın danışmanlığında (Eş Danışman Doç. Dr. Anara Kamalova) yürütülen "Hizmet Sektöründe Pazarlama Karması ve Hizmet Kalitesine Etkileri: İletişim Sektöründe Bir Uygulama" başlıklı doktora tezinden türetilmiştir. Çalışmanın bir önceki versiyonu, 22-25 Kasım 2011 tarihinde düzenlenen 16. Ulusal Pazarlama Kongresinde bildiri olarak sunulmuştur.

${ }^{2}$ Dr. - Kırgizistan-Türkiye Manas Üniversitesi İ̈BF, azamat.maksudunov@manas.edu.kg

(D) ORCID: 0000-0002-5010-513X
} 


\section{Giriş}

Hizmet sektörü hem gelişmiş, hem de gelişmekte olan ülkelerde önemli yer tutmaktadır. Bu sektörde faaliyet gösteren işletme sayıları her geçen gün artmakta ve rekabetin yoğunlaşmasına yol açmaktadır. Günümüzde işletmelerin ayakta kalabilmesi için tüketici isteklerine göre hareket etmesi, toplum çıkarlarını göz önünde bulundurması ve buna göre mal ve hizmetler üreterek müşteri tatminini esas alan pazarlama anlayışını benimsemesi zorunlu hale gelmektedir (Аристов, 2009, s. 11-18). İşletmelerin rekabet üstünlüğü kazanmaları ve uzun vadede piyasada kalabilmeleri için önem arz eden konular içerisinde hizmet pazarlaması ve hizmet kalitesi ön plana çıkmaktadır.

Hizmet pazarlaması literatürünün geldiği noktada her işletme birer hizmet işletmesi, her yönetici birer hizmet yöneticisi olarak görülmektedir (Rust, Zahorik ve Keininghan, 1996). Bilindiği gibi, günümüz koşullarında somut bir malı ek hizmetler olmadan veya tersine bir hizmeti somut ürünlerle desteklemeden tüketiciye satmak imkânsız hale gelmiştir (Zeithaml ve Bitner, 2000, s. 33). Bir ülkede hizmet sektörünün gelişimi, o ülkenin gelişmişlik düzeyinin de bir göstergesi olarak kabul edilmektedir. Diğer taraftan, kalite kavramı subjektif bir kavramdır. En basit şekliyle müşterinin gereksinimlerinin tatmini olarak tanımlanabilir (American Society for Quality-ASQ, 2011). Literatürde bu konuya yönelik yapılan çalışmalarda hizmet pazarlaması ve hizmet kalitesi arasında güçlü ve pozitif ilişkinin olduğu görülmektedir (Rafiq ve Ahmed, 1995; Iacobucci, Ostrom ve Grayson, 1995; Lee, Lee ve Yoo, 2000; Athanassopoulos ve Iliakopoulos, 2003; Nâsir, 2003; Aydın, Özer ve Arasıl, 2005; Ahmad ve Ahmad, 2008; Nimako ve Azumah, 2009). Bu konuyla ilgili araştırmaların farklı sektörlerde yapılmaya devam edildiği (Tayyar ve Dilşeker, 2012; Osman ve Sentosa, 2013; Cheng, Mansori ve Huei, 2014; Bucak ve Turan, 2016; WengKun, Yueh-Shian ve Li-Mei, 2017; Solimun ve Fernandes, 2018; Ping-Lung, Bruce ve Ching-Chin, 2019) ve son dönemlerde teknolojik hizmetler ve e-hizmetlere ilişkin çalışmaların yoğunlukta olduğu (Nga, Chovancová ve Tri, 2020; Ali vd., 2021; Sasono vd., 2021) görülmektedir.

Teknolojik gelişmeler dünyanın her tarafinda iletişim sektörünün hızla değişmesine yol açmıştır. Günümüzde internet, cep telefonları iletişim imkânlarımızı artırmakta ve hayatımızı kolaylaştırmaktadır. 2010 yılında küresel ölçekte 2 milyar civarında internet ve 4,5 milyar civarında cep telefonu kullanıcısı varken, 2021 yılı itibariyle bu göstergelerin sırasıyla 5,1 milyar ve 8 milyara ulaştığı görülmektedir (Internet World Stats (IWS), 2010-2021). Küresel ölçekte hızla yaşanmakta olan bu tür gelişmeler Kırgızistan'da da gözlemlenmektedir. Ülkede 2010 yılında 2 milyon civarında internet kullanıcısı ve ilk GSM operatörünün faaliyetine (1994) başladığ 1 yılda 98 bin civarında cep telefon kullanıcısı varken, 2021 yılında bu göstergelerin sırasıyla 3,1 milyona ve 5,2 milyona ulaştı̆g görülmektedir (DataReportal-DR, 2021). Ülkede son dönemlerde hizmet sektörünün nicel göstergeleri artsş göstermesine rağmen, hizmet kalitesi ve pazarlama uygulamaları ile ilgili ciddi açıkların olduğu dikkatleri çekmektedir. Özellikle Kırgızistan GSM sektörü ile ilgili sınırlı sayıda akademik çalışma bulunmaktadır (Özden ve Oktay, 2009; Polat ve Maksüdünov, 2015). Bu bağlamda çalışmanın temel amacı Kırgızistan'da GSM sektöründe hizmet pazarlaması ve kalite uygulamalarını değerlendirmektir.

\section{Hizmet Sektöründe Pazarlama Karması Bileşenleri}

Hizmet sektörünün ülke ekonomisine katkısı sadece gelişmiş ülkeler için değil, gelişmekte olan ülkeler için de göz ardı edilemeyecek düzeylere ulaşmışır. Üstelik sektörün büyümesi ve yaygınlaşması her geçen gün ilerlemekte ve hayatımızın tüm alanlarını kapsamaktadır. Belki de bu yüzdendir ki, hizmetlerin sınıflandırılmasında herkesçe kabul görmüş ortak bir yöntem henüz bulunmamaktadır. Bir tanıma göre, hizmet, insan veya makineler tarafindan insan gayretiyle üretilen ve tüketicilere doğrudan fayda sağlayan, fiziksel olmayan ürünler şeklinde tanımlanmaktadır (Karahan, 2006, s. 27). Hizmetler ihtiyaçları giderme şekline göre tamamen soyut olabileceği gibi, somut özellikler de taşıyabilir. Diğer taraftan, ihtiyaçları giderme aracına göre insan gücüne dayalı olabileceği gibi, makine veya teknolojiye dayalı da olabilir (Миронова, 2003). Hizmetlerin sinıflandırılması sadece istatistiki verilerin bir sistematik içerisinde toplanmasını sağlamakla sınırlı değildir. Uygulanacak pazarlama stratejileri ve politikaları hizmetin türüne göre de farkl1lık göstermektedir (Lovelock, 1983). 
Tamamen soyut hizmetler

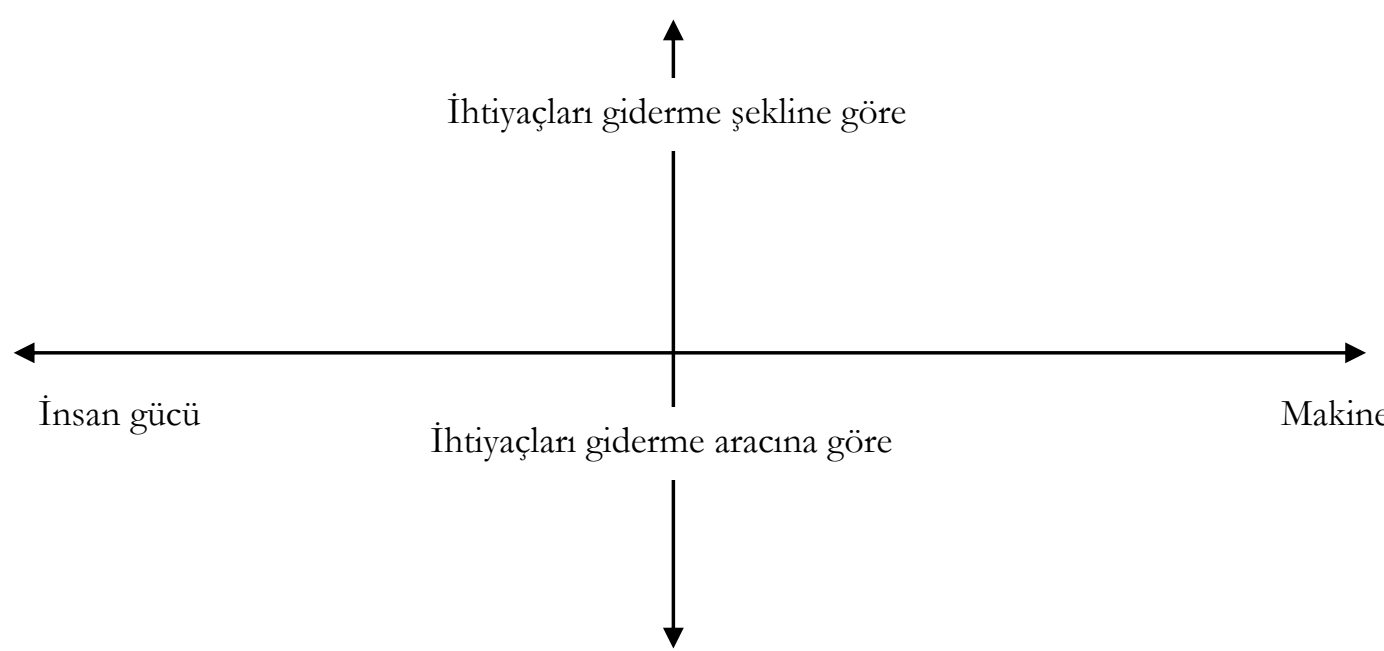

Somut özellikleri olan hizmetler

Şekil 1. Hiæmetlerin Simflandirlması (Mиронова, 2003)

Hizmet sektöründe faaliyet gösteren bir işletmenin pazarlama yöneticisi hizmet türünün yanı sıra, ürünlerine ait dört temel spesifik özelliği de göz önünde tutmalıdır. Bu temel özellikler (Rust vd., 1996, s.710); hizmetin soyutluğu, hizmetin bölünmezliği, hizmetin değişkenliği ve hizmetin dayanıksızlığıdır. Hizmet pazarlamasının temel dayanaklarının sözü geçen özelliklerden oluştuğu bilinmektedir. Hizmet sektörünün gelişmesine paralel olarak pazarlama uygulamaları da gelişme göstermiştir.

Pazarlama 1960'lı yıllardan itibaren hızlı bir gelişme kaydetmiş ve pazarlama karması olarak bilinen kavram ortaya çıkmıştır. Pazarlama karması - pazarlamanın çeşitli araçlarından (ürün, fiyat, dağıtım ve tutundurma) koordineli bir şekilde yararlanılmasıdır ve ilgili literatüre pazarlamanın 4P'si olarak aktarılmıştır (McCarthy, 1964; Goi, 2009). Ancak, hizmet pazarlaması, geleneksel pazarlamanın 4P'sinden daha fazlasını gerektirmektedir. Yani, hizmet pazarlaması geleneksel pazarlama karmasına ek olarak katılımcıları, süreç ve fiziksel ortamı da kapsamaktadır ve literatürde pazarlamanın 7P'si olarak bilinmektedir (Zeithaml ve Bitner, 2000, s. 19). Tablo 1'de ayrıntılarının yer aldığ1 pazarlama karması elemanlarından hizmet sektörü ile ilgili olan ek bileşenlere bakacak olursak, hizmet üretimi önemli ölçüde insan gücüne dayanmakta, yani tüketicilerin satın aldığ1 hizmetlerden memnuniyeti katılımcılardan büyük oranda etkilenmektedir.

Tablo 1. Pąarlamada «4P - 4C»ve « $7 P-7 C »$

\begin{tabular}{|c|c|c|c|c|c|}
\hline & «P»» & \multicolumn{2}{|c|}{$« 4 C »-\langle 7 C »$} & \multicolumn{2}{|c|}{ «P» } \\
\hline Product & Ürün & $\begin{array}{l}\text { Consumer wants } \\
\text { and needs }\end{array}$ & $\begin{array}{l}\text { Tüketici istek ve } \\
\text { ihtiyaçları }\end{array}$ & Product & Ürün \\
\hline Price & Fiyat & Cost to satisfy & Tüketiciye maliyeti & Price & Fiyat \\
\hline Place & Dağıtım & Convenience to buy & Satın alma kolaylığ1 & Place & Dağıtım \\
\hline \multirow[t]{4}{*}{ Promotion } & Tutundurma & Communication & İletişim & Promotion & Tutundurma \\
\hline & & Customer Care & Müşteri hizmetleri & People & İnsan \\
\hline & & Connectivity & Etkileşim & Process & Süreç \\
\hline & & Content & İçerik & Physical Evidence & Fiziksel kanıt \\
\hline
\end{tabular}

Kaynak: Zeithaml ve Bitner, 2000, s. 19

Buradaki katılımcı işletmenin personeli ve daha önce aynı işletmenin hizmetinden yararlanan bir müşterisi de olabilir. Hizmet üreten ve pazarlayanlarla birlikte, hizmet faaliyet alanı içerisinde bulunan hizmet destekleyicileri ve tüketiciler de dâhil olmak üzere yer alan tüm insanlar katıllmcilar olarak adlandırılır. Kaliteli bir hizmet için katılımcı faktörü tek başına yetersizdir. Üzerinde durulması gereken önemli diğer bir faktör süreçle ilgilidir. Süreç, hizmetin üretiminden tüketicisine kadar izlediği yol, hizmetin hızı gibi konuları içermektedir. Süreç yönetimi, tüketicinin istediği kalitedeki bir hizmetin istediği yerde ve 
istediği zamanda hazır bulundurmasılyla ilgili düzenlemelerdir. Bilindiği gibi, hizmetler üretildiği yerde tüketilir ve tüketici işletmenin fiziksel ortamını görme ve değerlendirme şansına sahiptir. Fiziksel ortam veya fiziksel olanaklar işletmelere olumlu bir imaj kazandırır. Dolaysıyla, hizmet işletmeleri tüketicilerin beklentilerine uygun dış ve iç görünüme, personelin dış görünümüne önem vermeleri gerekmektedir (Аав $А$ о, 2005, s. 43).

İlgili literatürde pazarlamanın '7P' modelinin yanı sıra başka modellerin de olduğu bilinmektedir (Новаторов, 2000, s. 40-55; Grönroos, 1982, s. 30-41; Аав $о$ б, 2005, s. 1-997). 1970'lerde Avrupa ülkelerinde ve ABD'de hizmet pazarlaması ayrı bir disiplin olarak gelişmeye başlamış ve bunun öncülerinden biri de J. Rathmell (1974) olmuştur. Rathmell hizmet pazarlaması ile ilgili Şekil 2'de gösterilen modeli önermiştir (Grönroos, 1982, s. 32).

Somut Ürün

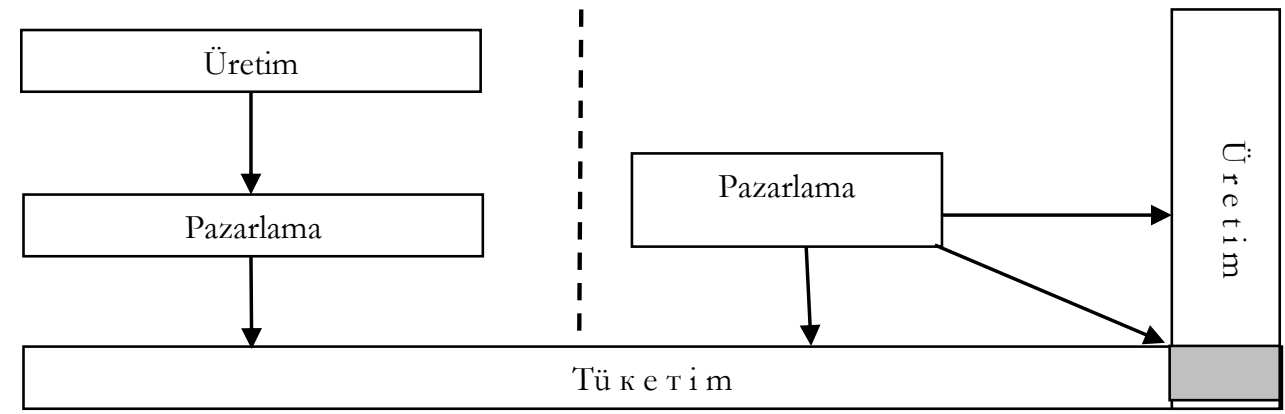

Hizmet

İnteraktif pazarlama

Şekil 2. Rathmell'in Hižmet Pazarlaması Modeli (Grönroos, 1982, s. 32)

Modelde somut ürün ile hizmet pazarlaması arasındaki fark gösterilmektedir. Rathmell'e göre somut ürünlerde birbiri ile bağlantllı, ancak birbirinden ayr1 düşünülebilecek üretim, pazarlama ve tüketim süreçleri yer almaktadır. Buna karşlık, hizmet sektöründe üretim ile tüketim eş zamanlı gerçekleştirilmektedir. Bununla beraber, hizmet sektöründe geleneksel pazarlamanın yanı sıra üretici ile tüketici arasındaki etkileşim de çok önemlidir. Yani, işletmenin pazarlama faaliyetleri geleneksel pazarlama ve etkileşimli pazarlama faaliyetlerinden oluşmaktadır.

Rathmell'in modeli hizmetin ayrrlmazlık, yani üretim ve tüketiminin eş zamanlllık özelliğine vurgu yapmaktadır. Buna karşlık, Eiglier ve Langeard (1976) tarafindan önerilen bir başka model, hizmet sektöründe katılımcı ile fiziksel kanıtların önemine vurgu yapmaktadır. Söz konusu modelde işletme ikiye ayrılmış; birincisi müşteriye gözükmeyen kısımlar (ofisler, depolar vs.), ikincisi ise hizmetin sunulduğu ve müşterilerin doğrudan gördükleri kısımlardır. Modele göre, hedef müşteri hizmeti sunan personelin davranışlarından, işletmenin sahip olduğu fiziksel ortamdan ve hizmet esnasındaki diğer müşterilerin davranışlarından etkilenmektedir (Новаторов, 2008, s. 44).

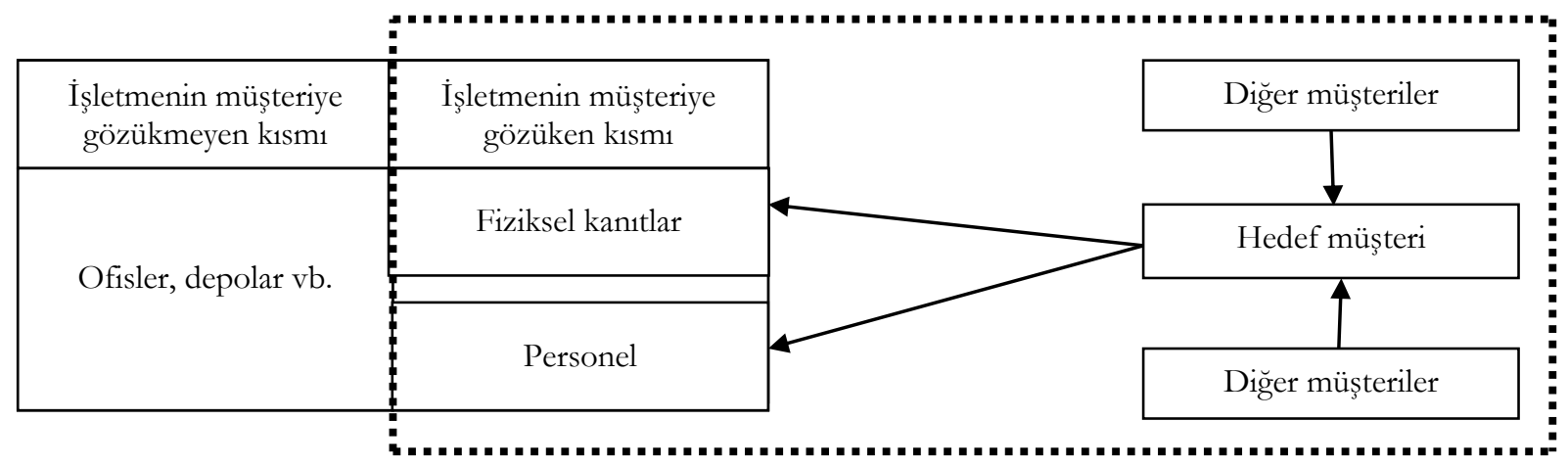

Şekil 3. Eiglier ve Langeard'n «Servuction» Modeli (Hоваторов, 2008, s. 44) 
$\mathrm{Bu}$ alanda diğer bir çalışma Lovelock (2005) tarafindan yapılmıştır. Çalışmasında hizmet pazarlamasının '7P'sine sekizinci 'P' olarak verimlilik ve kaliteyi (Productivity and quality) eklemiştir. Lovelock'a göre hizmet işletmesinde pazarlama karması sekiz temel bileşenden oluşmaktadır. Onların ilk yedi tanesi bilinen pazarlama karması elemanlarıdır. Sekizincisi yazarın katkısı olarak önerilmiştir. Tabii ki rekabet ortamında verimlilik ve kalite işletmeler açısından olmazsa olmaz konular içerisinde yer almaktadır.

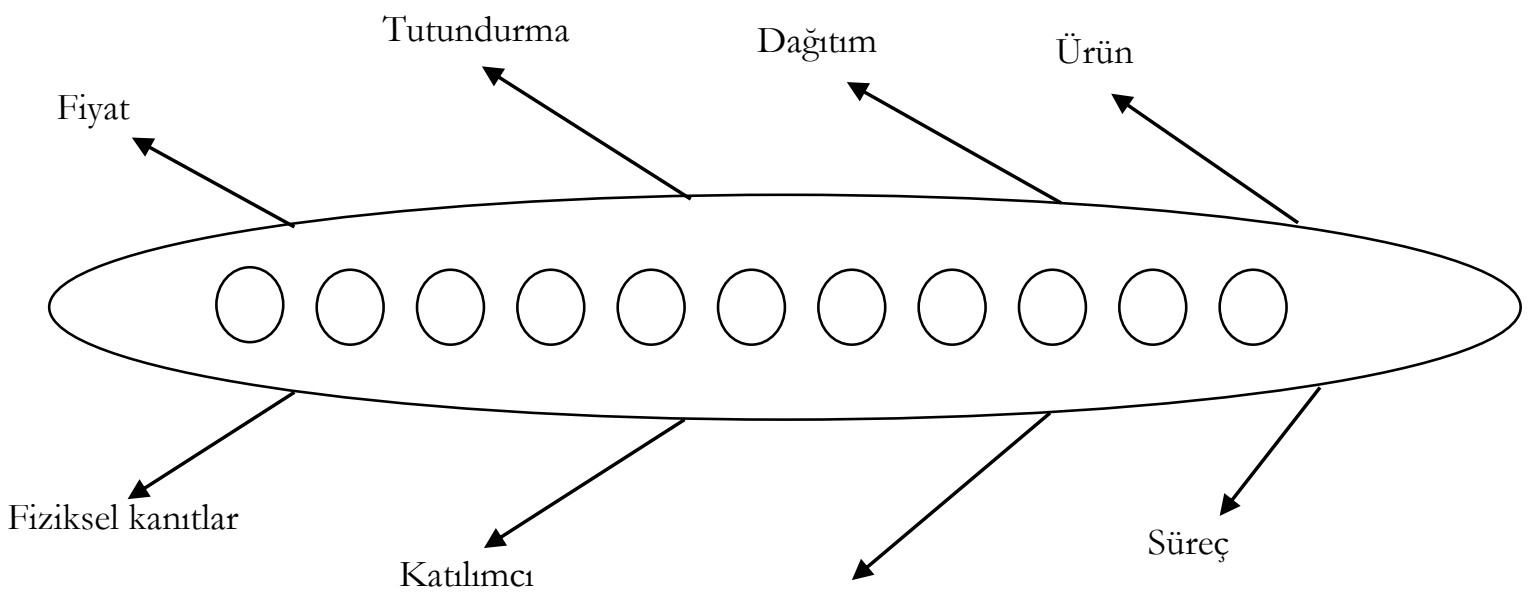

Verimlilik ve kalite

Şekil 4. Ch. H. Lovelock'un Hizmet Paz̧arlamast Modeli (1aв.лok, 2005, s. 51)

Hizmet sektöründe pazarlama karması işletme yönetimi tarafından kontrol edilebilir değişkenlerdir. Hizmet işletmeleri bu karmayı yönetirken, sadece yönetim ile pazar arasındaki ilişkileri değil, yönetim ile personel (içsel pazarlama), personel ile pazar (etkileşimli pazarlama) arasındaki ilişkileri de göz ardı etmemelidir. Tüm bu faktörler sonuç olarak hizmet kalitesini etkilemektedir.

\section{Hizmet Kalitesi Yönetiminde Pazarlamanın Yeri}

Kalite subjektif bir kavramdır. En basit şekliyle müşterinin gereksinimlerinin tatmini olarak tanımlanabilir (ASQ, 2011). Ancak, kalitenin tanımlanması esas amaç değil, esas olan işletme ile ilgili olan tüm tarafların (yönetim, personel, tüketici, devlet vb.) kalite denildiğinde aynı şeyi kastedip kastetmediğini tespit etmektir (Хаксевер, Рендер, Рассе, ve Мердик, 2002, ss. 437-438). Yani, kalite bir anlamda tüketicinin işletmeden beklenti düzeyidir. Literatürde kalite ile ilgili ilk girişim ve çalş̧alar 19. yüzyılda başlamıştır. Bu konuda, ilgili literatürde en çok rastlanan bilim adamları olarak Feigenbaum, Juran, Deming, Ishikawa vd. bilinmektedir.

Kalite yönetimi, kalite standartları alanında Uluslararası Standartlar Örgütü (ISO), Amerikan Kalite Kontrol Derneği (ASQ), Avrupa Kalite Kontrol Örgütü (EOQ) gibi birçok ulusal ve uluslararası kuruluş faaliyet göstermektedir. Bunların içerisinden ISO'nun ortaya koyduğu kalite standartları bugün 161 ülkede 750.000 'in üzerinde kuruluş tarafindan kullanılmaktadır (International Organization for StandardizationISO, 2010). Bu örgütlerin faaliyetleri hizmet kalitesine olan ilginin artmasına neden olmuştur.

İlk zamanlar kalitenin tanımlanması ve ölçülmesine yönelik çalısmalarda kalite kavramı daha ziyade somut ürünlerin özellikleri dikkate alınarak tanımlanmıştır. Fakat 1970'lerden sonra dünyada hizmet sektörünün hızla gelişmesine paralel olarak hizmet kalitesi de sık sık tartısılmaya başlamıştır.

Hizmet kalitesine ilişkin ilk model Grönroos (1982) tarafindan önerilmiştir. Grönroos hizmet kalitesinin (SQ - Service Quality) boyutlarını üçe ayırmıstır:

$$
\mathrm{SQ}=\mathrm{f}(\mathrm{CI}, \mathrm{TQ}, \mathrm{FQ})
$$

Birincisi kurumsal imaj olup (CI - Corporate Image), tüketicilerin hizmet kalitesini değerlendirirken işletme imajını dikkate almalarından oluşmaktadır. İkincisi olan teknik kalite ise (TQ - Technical Quality), bir hizmetin göreceli olarak nicel yönlerine işaret etmektedir. Üçüncüsü fonksiyonel kalitedir (Functional Quality) (Grönroos, 1982, ss. 33-34). 
Daha sonra Parasuraman, Berry ve Zeithaml (1988) tarafindan SERVQUAL ve Cronin ve Taylor (1992) tarafindan SERVPERF modeli geliştirilmiş ve ikisi de literatürde yaygin kabul görmüştür Söz konusu iki model hizmet kalitesini ölçmek için 22 sorudan oluşan bir ölçek kullanmaktadır. Fakat SERVPERF modeline göre hizmet kalitesi (SQ - Service Quality) sadece alg1lamanın (PQ - Perceived Quality) bir fonksiyonu olduğunu ve doğal olarak ölçeğin tek boyutlu olması gerektiğini savunmaktadır.

$$
\mathrm{SQ}=\mathrm{f}(\mathrm{PQ})
$$

Buna karşıllk, SERVQUAL modeli ise beş temel boyuttan (Fiziksel Görünüm, Güvenilirlik, Yanıt Verebilirlik, Güvence, Empati) oluşmaktadır Yazarlara göre hizmet kalitesi (SQ - Service Quality) beklentiler (EQ - Expected Quality) ve algilamaların (PQ - Perceived Quality) bir fonksiyonudur.

$$
\mathrm{SQ}=\mathrm{f}(\mathrm{PQ}, \mathrm{EQ})
$$

Literatürde sözü geçen ölçeklerin sıkça tartışmaya konu edildiği ve çalışmaların bir kısmının bu modeli geliştirmeye, diğer bir kısmının ise bu modeli eleştirmeye yönelik olduğu görülmektedir. Bunun yanı sıra, hizmet kalitesini ölçmeye yönelik yapılan çalışmalarda bu beş boyutun dışında fiyat, imaj gibi faktörlerin de araştırma kapsamına dâhil edildiğine rastlanmaktadır (Nimako ve Azumah, 2009; Zhang, Feng, 2009).

Literatür taraması sonucunda hizmet kalitesinin boyutları olarak tanımlanan değişkenlerin çoğu aslında pazarlama karması elemanlarını oluşturmaktadır. Dolayısıyla, beklenen ve algılanan hizmet kalitesine pazarlama karmasının büyük ölçüde etki ettiği öne sürülebilmektedir.

Hizmet pazarlaması, hizmet kalitesi ile ilgili yapılan literatür taraması sonucuna dayalı olarak hizmet sektöründe pazarlama ve kalite yönetim modeli aşağıdaki şekli almaktadır.

$\mathrm{SQ}=\mathrm{f}(\mathrm{E} 7 \mathrm{P}, \mathrm{P} 7 \mathrm{P})$

SQ - Service Quality - Hizmet Kalitesi

E7P - Expected 7P - Beklenen Pazarlama Karması

P7P - Perceived 7P - Alg1lanan Pazarlama Karmas1

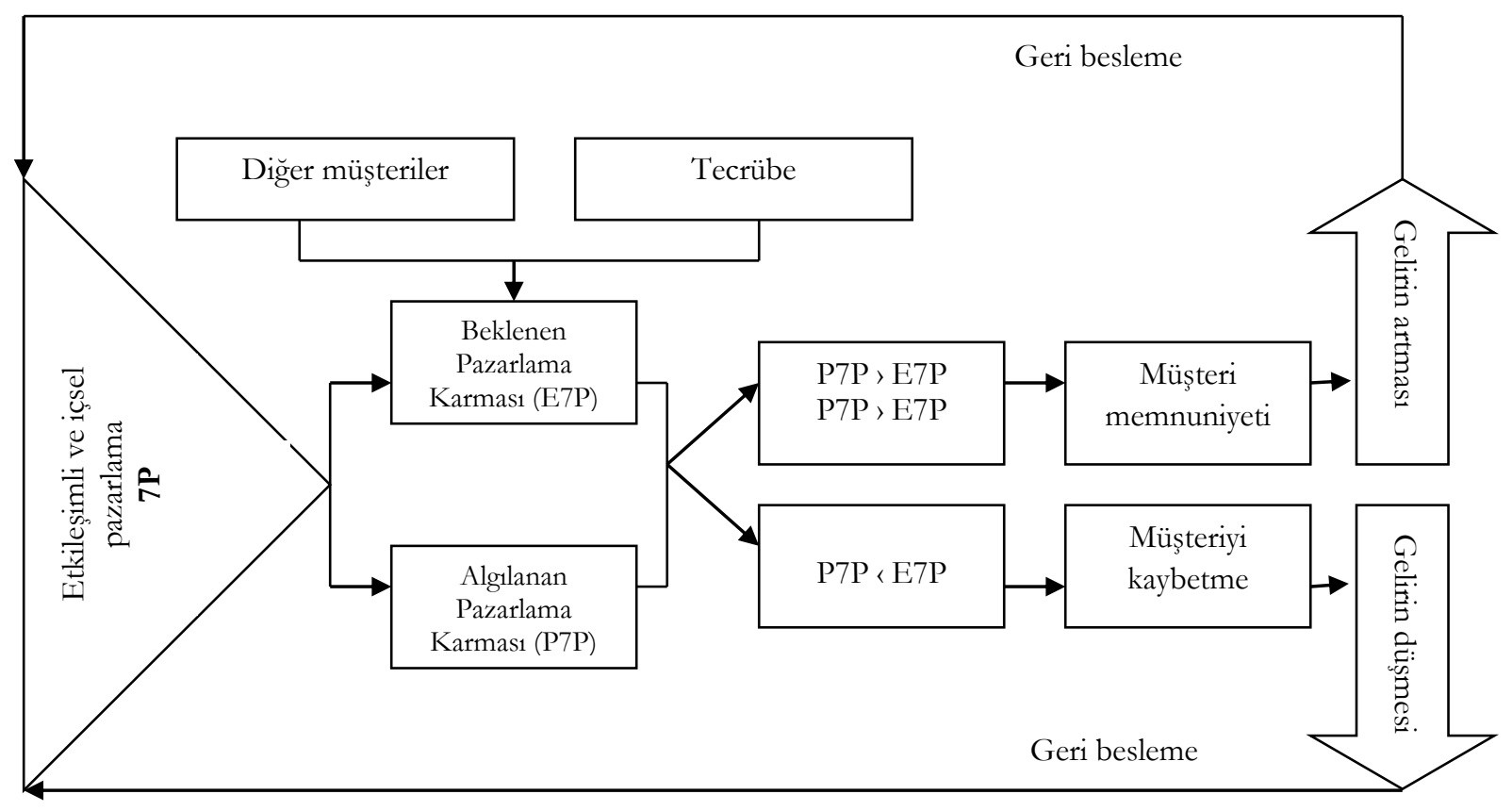

Şekil 5. Önerilen Hizmet Paz̧arlaması ve Kalite Yönetim Modeli (Literatüre dayalı olarak yazarlar tarafindan oluşturulmustur)

Hizmet kalitesinin müşterilerin pazarlama performansından beklenti ve algılarına göre şekillendiği söylenebilir. Diğer bir ifadeyle, işletmeler pazarlama karması bileşenlerini müşterilerin beklediği düzeye eşit veya beklentilerinin üzerinde gerçekleştirebilirlerse, müşterilerin algıladığı hizmet kalitesi pozitif yönde 
olmakta ve müşteri memnuniyetine yol açmaktadır. Teorik olarak var olan söz konusu değişkenler arasındaki ilişkilerin farklı ülkelerde, farklı sektörlerdeki durumları değerlendirilmelidir.

\section{Kırgızistan'da GSM Sektöründe Pazarlama ve Kalite Uygulamaları}

Kırgızistan Sovyetler Birliğ̊’nin dağılmasıyla 1991'de bağımsızlı̆̆ını ilan etmiş ve dünya ekonomisine entegre olma yönünde piyasa ekonomik sistemine geçiş sürecini başlatmıştır. Dolayısıyla, piyasa ekonomisinin önemli öğelerinden olan özel mülkiyet, girişimcilik, rekabet, pazarlama gibi kavramlar ile ilk defa karşı karşıya kalmıştır. Her ne kadar, pazarlamaya planlı ekonomik sistemde de ihtiyaç olduğu, Sovyet döneminde de pazarlama teorisinin ve uygulamalarının öğrenilmesine yönelik çalışmaların yapıldı̆̆ı söylense de (Fox, Skorobogatykh ve Saginova, 2005), faaliyetler ülke üst yönetiminde yer alan ve daha çok uluslararası ticaretten sorumlu dar bir çevre ve belirlenmiş ideolojilerin sınırları içerisinde kalmıştır. Diğer taraftan, yeni oluşmakta olan özel sektörde yoğun bir rekabet söz konusu olmadığı için, yerli girişimci ve yöneticilerin müşteri odaklı pazarlama konusunda yeterli bilgi ve deneyime sahip olmaması nedeniyle aradan geçen 15 yıllık sürede işletmeler üretim ve satış anlayışı ile faaliyetlerine devam etmek zorunda kalmıştır. O dönemdeki Kırgızistan piyasasında pazarlama anlayışı, pazarlamayı gerektiren ortamın henüz oluşmadığından yabancı sermayeli olarak kurulan işletmeler de müşteri odaklı pazarlama yaklaşımını bilinçli olarak uygulamamışlardır (Maksüdünov, 2007). 2010 yllında hala birçok sektörde işletmeler kısa süreli kar elde etmenin ötesine geçememişlerdir. Ancak, o dönemde uygulanmakta olan özelleştirme çalışmaları ve ülke içinden ve dışından yatırımcıların katılmalarıyla her alanda hem rekabet yükselmekte, hem de tüketicilerin ekonomik gücü, tüketim bilinci ve tercih imkânları da artmıştır. 1991 yllında hizmet sektörünün GSMH'deki pay1 \% 28 iken 2010 yılında \% 47’ye ulaşmıştır (KC Milli İstatistik Komitesi-KC MİK, 2011) ve 2020 y1l itibariyle de \% 49,6 olduğu bilinmektedir (World Bank, (WB), 2021). Hizmet sektörü içerisinde, hızlı büyümesi ve teknolojiye dayalı olması ile dikkat çeken alt sektörlerden biri GSM sektörüdür.

GSM sektörü ağırlıklı olarak makine ve teknolojiye dayalı bir hizmet türüdür ve hizmet sektörü içerisinde önemli bir yer tutmaktadır. Daha önce değinildiği gibi, hizmet sektörünün GSMH'deki payı \% 50 civarında olup (81174,1 milyon som), bu rakamın \% 11'i GSM sektörüne denk gelmektedir (KC MIK, 2010). Kırgızistan'da ilk GSM operatörü 1994'te faaliyetine başlamıştır. Kırgızistan Cumhuriyeti Milli İletişim Ajansı (KC MİA) verilerine göre, 2010 itibariyle, bu sektörde 7 operatörün toplam abone sayısının 5.275 .477 olduğu ve 2020 yll itibariyle operatör sayısının 4'e düştüğ̈̈, ancak kullanıcı sayısının ise 7.315.943'e çıktığ1 görülmektedir (KC MİA, 2010, 2020). Sektörün özellikleri, rekabet koşulları, işletme sahiplerinin tecrübeleri nedeniyle diğer hizmet sektörlerine kiyasla daha aktif bir pazarlama politikası yürütmektedirler.

GSM sektöründe pazarlama uygulamalarını pazarlama karması bileşenleri kapsamında 2010 yılı için değerlendirdiğimizde ve 2021 yllı itibariyle yaşanan değişimleri özetlediğimizde aşağıdaki tablo karşımıza çıkmaktadır.

Tablo 2. GSM Sektöründe Pazarlama Karması Uygulamalarnn Genel Özellikleri

\begin{tabular}{|c|c|}
\hline «P» & Uygulama özellikleri ve açıklamalar \\
\hline & $\begin{array}{l}\text { - DAMPS, CDMA, GSM, 3G standartlarında GSM hizmeti sunmaktadırlar. } \\
\text { - Call Center, numara değiştirme, kaybolan sim kartların değiştirilmesi, internet hizmeti bulunmaktadır. } \\
\text { - Kullanıcı ile operatör arasında resmi bir sözleşme yapılmamaktadır. } \\
\text { - Son } 15 \text { yılda bu sektöre } 400 \text { milyon \$ civarında yatırım yapılmış olup, } 10 \text { binlerce istasyon kurulmuştur. } \\
\text { - GSM hizmetinin ürün hayat eğrisinin gelişme aşamasında olduğu söylenebilir. } \\
\text { - } 2021 \text { yllına geldiğimizde 4G internet, ürün çeşitliliğindeki artış, kullanıcılar ile resmi sözleşmelerin } \\
\text { yapıldığını görülmektedir. }\end{array}$ \\
\hline 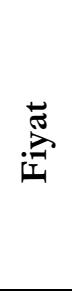 & $\begin{array}{l}\text { - Kırgızistan GSM sektöründe fiyat politikası pazarlama anlayışı çerçevesinde değil, piyasada geçici olarak } \\
\text { meydana gelen şartlara göre şekillenmektedir. } \\
\text { - GSM sektöründe rekabet genel olarak fiyat politikasını belirlemek ile birlikte, müşteri memnuniyeti ve } \\
\text { sadakati açısından yeterli olmadığ1 söylenebilir. } \\
\text { - Mevcut fiyatların gerçekçi olmadığ1, talep fazlalığından kaynaklanan yüksek fiyatlar söz konusudur. } \\
\text { - } 2021 \text { yılına geldiğimizde fiyat politikasında önemli bir değişim olmamakla birlikte, } 2010 \text { yllına göre daha } \\
\text { gerçekçi bir fiyat düzeyi olduğu söylenebilir. }\end{array}$ \\
\hline
\end{tabular}




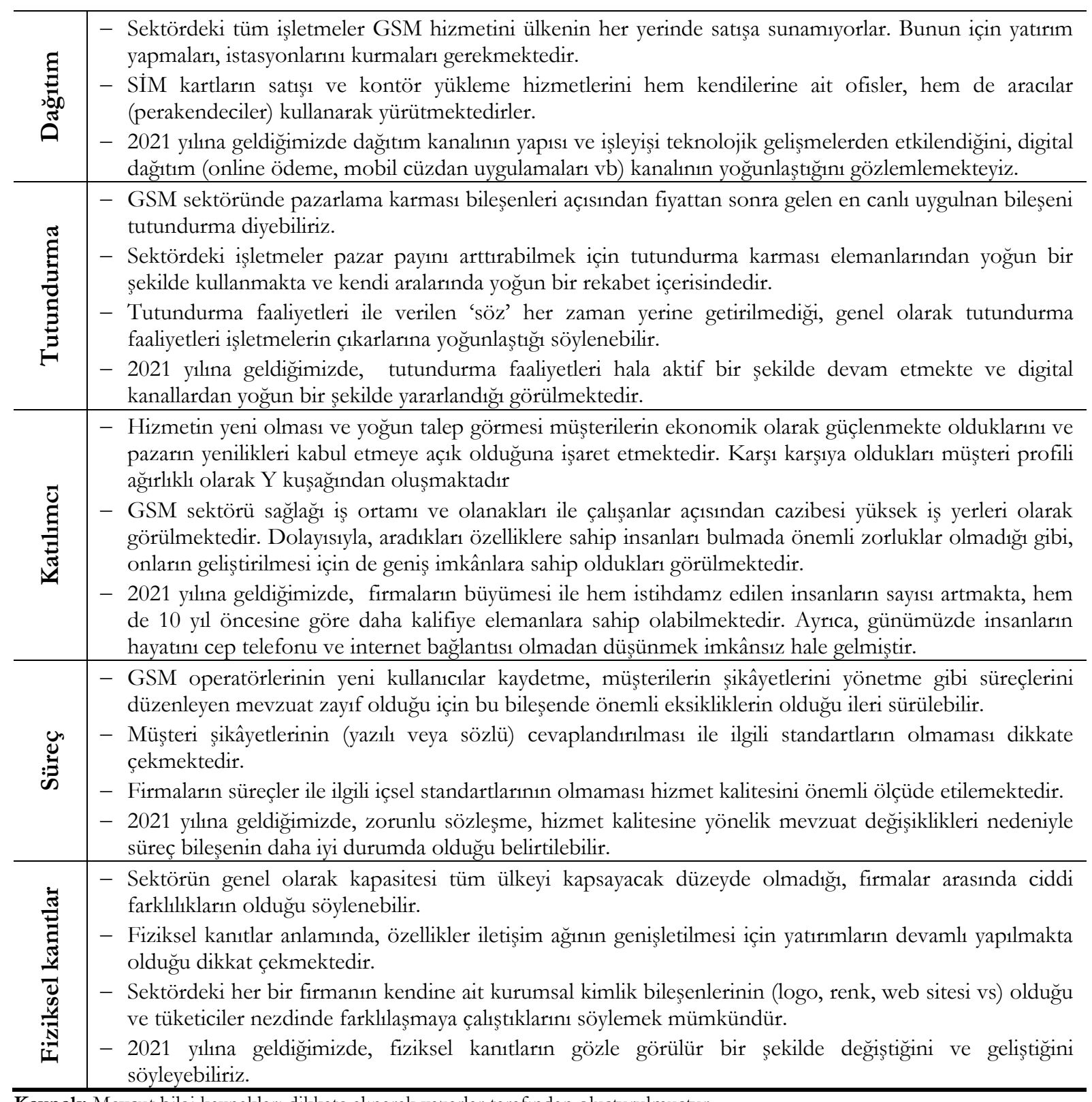

Kaynak: Mevcut bilgi kaynakları dikkate alınarak yazarlar tarafından oluşturulmuştur.

GSM sektörünün özellikleri, rekabet koşulları ve işletme sahiplerinin tecrübeleri de yansıdığı için, bu sektör diğer hizmet sektörlerine göre daha aktif bir pazarlama politikası izlemektedir. Ancak, pazarlama karması bileşenleri açısından değerlendirdiğimizde fiyat, tutundurma ve fiziksel kanıtlar gibi bazı elemanlarda yoğunlaştı̆̆ görülmektedir. Ancak, pazarlama karmasının sinerji yaratabilmesi için bütünleşik bir yaklaşım ve müşteri odaklı pazarlama anlayışının olması gerekmektedir. Hizmet kalitesi müşterilerin bekledikleri ve algıladıkları pazarlama performansina bağlı ise, bu konuda mevcut işletmeler ne kadar başarılıdır? Bu konuların saha araştırmaları ile desteklenmesi gerekmektedir.

Kırgizistan'da kalite konusunda uygulamalar (standartlar, mevzuat vb.) yeni değildir ve Sovyet döneminde geliştirilen araçlar (ГOCT-standart) hala kullanılmaktadır. Piyasa ekonomisine geçiş sürecinde birçok gelişmeler yaşanmıştır. 1992 yllından başlayarak ülkede devlet sertifikasyon sistemi geliştirilmeye, teknik mevzuat, ulusal ve uluslararası standartlar, sektörel ve kurumsal standartların oluşturulma süreci başlamıştır (Токсобаева ve Токсобаев, 2007, s. 200). 1992'de 'Tüketici Hakları Kanunu’ kabul edilmiş, 1999'da ISO standartların Kırgızistan'da adaptasyonu ile ilgili uluslararası kuruluşlarla ortak çalışmalar başlatılmıştır. GSM sektöründeki işletmeler de hızla uluslararası standartları benimsemekte ve bu konuda da kendi aralarında bir rekabet içerisinde bulunmaktadırlar.

Kırgızistan'da hizmet sektörü ve özellikle GSM hizmetinin teknik kalitesine yönelik bir takım somut adımların yapılmakta olduğu bir gerçektir. Ancak, hizmet kalitesi açısından bu yeterli değildir. Piyasa 
ekonomik koşullarında firmaların rekabet avantajı elde edebilmeleri için teknik kalite kadar, fonksiyonel kalite de önemli yer tutmaktadır (Grönroos, 1982). İlgili literatüre baktı̆̆ımızda, farklı ülkelerde yapılan araştırmaların hizmet kalitesinin fonksiyonel boyutuna yoğunlaştı̆̆ söylenebilir (Athanassopoulos ve Iliakopoulos, 2003; Woo ve Fock, 1999; Ahmad ve Ahmad, 2008; Nimako ve Azumah 2009). Kirgizistan örneğinde GSM sektöründe hizmet kalitesi ile doğrudan ilgili olmamakla birlikte, bu sektördeki pazarlama ve yönetim konularını içeren sınırlı sayıda akademik çalşsmalar (Özden ve Oktay, 2009; Polat ve Maksüdünov, 2015) bulunmaktadır.

\section{Sonuç ve Öneriler}

Günümüzde işletmelerin pazarlama anlayışını benimsemesini zorunlu kılan belli başlı eğilimler söz konusudur. Piyasaya arz edilen mal ve hizmetler her geçen gün artmaktadır. Yani işletmeler yoğun bir rekabet ortamında faaliyet göstermektedir. Küresel bazda, tüketicilerin seçim şansının yükselmesi, alım güçlerinin artması, tüketim bilinçlerinin artması nedeniyle tüketiciler güçlü konuma gelmektedir. Diğer taraftan, çevre sorunlarının küresel boyut kazanması işletmeleri sadece tüketici ihtiyaçlarına odaklanmakla sınırlı kalmayıp toplum çıkarlarını da göz önünde bulundurmasını zorunlu kılmaktadır. Ayrıca, kalitenin belirlenmesinde tüketicilerin beklenti ve algılamalarının esas alınması zorunlu olmaktadır. Kalite düzeyinin yükseltilmesi ile rekabet üstünlügü kazanılmakta, firma pazar payını artırmakta ve prestij sağlamaktadır. $\mathrm{Bu}$ koşulları sağlayamayan işletmeler piyasadan çekilmek zorunda kalmaktadır. İşletme yönetiminin kararları sağlam bir bilgiye dayalı olarak alınması önem taşımaktadır. Bu açıdan araştırma faaliyetleri ön plana çıkmaktadır (Аристов, 2009, s. 11-18). Özellikle, pazarlama ve kalite konularında bilgiye dayalı karar verme eğilimi gözlemlenmektedir. Pazarlama ve kalite ile ilgili literatür incelendiğinde, bir birini tamamlayan iki unsur olarak karşımıza çıkmaktadır. Kalite müşteri gözüyle değerlendirilmekte ve hizmet kalitesinin pazarlama performansına dayalı olarak şekillendiği görülmektedir.

Küresel ölçekte yaşanmakta olan bu tür eğilimler ulusal bazda işletmelere de etkisini göstermektedir. Kırgızistan'da özel sektör henüz gelişme aşamasında olup, gelişmiş ülkelerdeki piyasa koşulları tam olarak oluşmuş değildir. Hizmet sektörü hızla gelişmekte ve özellikle GSM sektörü karll1ı̆̆ en yüksek sektörlerden biri olarak dikkat çekmektedir. Bu sektörde uygulanmakta olan pazarlama ve kalite uygulamalarının değerlendirilmesi (2010) sonucunda, işletmelerin ticari faaliyetlerinde pazarlamanın güncel yaklaşımlarına, müssteri odaklı anlayışına yeterli düzeyde yer verilmediği söylenebilir. 2021 yılında hizmet pazarlaması ve dolayısıyla hizmet kalitesine ilişkin gelişmelerin yaşandığı görülmektedir. Ancak, piyasa koşullarından kaynaklanan şartlara bağlı olarak işletmelerin hala müşteri odaklı, kalite odaklı pazarlama anlayışını benimsemedikleri de bilinen bir gerçektir. Sektörün genel olarak etkinliği, sektörde faaliyet gösteren işletmelerin uzun dönemli başarıları ancak kaliteli hizmet sunmakla gerçekleşebilecektir. $\mathrm{Bu}$ doğrultuda, sektörle doğrudan ilgilenen devlet kurumlarına, işletme yöneticilerine ve bu alanda bundan sonra yapılacak bilimsel çalısmalara yönelik olarak öneriler geliştirilebilir.

İlgili devlet kurumları ulusal ve uluslararası kalite standartlarının işletmeler tarafindan uygulanması, sektörde serbest rekabet koşullarının oluşturulması, tüketici haklarının korunmasına yönelik hukuki altyapının geliştirilmesi ile ilgili çalışmalarını sürdürmelidir. GSM işletmelerin kalite standartlarını benimsemeleri ve uygulamaları teşvik edilmelidir.

İşletmeler müşteri memnuniyetini esas alan anlayışı bir kurum kültürüne dönüştürmesi gerekmektedir. Hizmet kalitesi, pazarlama ve diğer tüm işletme faaliyetleri ile ilgili kararların pazarlama araştırmalarından elde edilen sağlam bilgilere dayandırmalıdırlar. Yani, araştırmaya önem verilmeli ve araştırma giderlerine yatırım olarak bakılmalıdır. Pazarlama karması içerisinden fiyatla ilgili düzenlemelerde mümkün olduğu kadar müşteri odaklı olmaya, fiyat politikasının istikrarlı olmasına özen göstermelidir. Müşterileri şikayetleri hızlı ve düzenli olarak değerlendirilmeli ve müşteriye hizmeti doğrudan sunan personele önem verilmelidir. Bu bağlamda, insan kaynakları yönetiminin son gelişmeleri takip edilmeli, çalışanlara iç müşteri gözüyle bakılmalıdır. Bu konuda daha detaylı bir araştırma mevcut ve potansiyel müşteri kitlesi üzerinde yapılarak, hizmet kalitesine ilişkin içsel standartlar oluşturulabilir. İşletmeler bütünleşik pazarlama yaklaşımı ile hareket etmeli ve kaliteli hizmetin sürdürülebilir gelişmenin anahtarı olduğunu unutmamalıdırlar.

Hizmet pazarlaması ve hizmet kalitesine ilişkin sorunlar, Kırgızistan'da GSM sektörüne özgü bir durum değildir. Bilindiği gibi, hizmet kalitesi ve müşteri memnuniyetine ilişkin sorunlar ülkemizde birçok devlet ve özel sektör kurum ve kuruluşlarının gelişmesine engel olmaktadır. Sonuç olarak, pazarlama ve kalite anlayışı sadece bir ürünün veya bir işletmenin değil, genel olarak toplum hayatının kaliteli olmasını, toplumun mutlu olmasını amaçladığı unutulmamalıdır. 


\section{Etik Beyan}

"Kurgzzistan GSM Sektöründe Hižmet Pazarlaması ve Hizmet Kalitesi Uygulamalarmmn Değerlendirilmesi” başliklı çalışmanın yazım sürecinde bilimsel kurallara, etik ve alıntı kurallarına uyulmuş; toplanan veriler üzerinde herhangi bir tahrifat yapılmamış ve bu çalışma herhangi başka bir akademik yayın ortamına değerlendirme için gönderilmemiştir. Bu araştırma derleme bir makale olduğundan etik kurul kararı zorunluluğu bulunmamaktadir.

\section{Kaynakça}

Ahmad, A. ve Ahmad, H. (2008). Marketing mix drivers of clients satisfaction in technology - enabled service: study of Nigerian GSM subscribers. Communication of the IBIMA, 1, 84-90. Erişim adresi: https://ibimapublishing.com/articles/CIBIMA/2008/643567/643567.pdf.

Ali, B. J., Saleh, Akoi, S., Abdulrahman, A. A., Muhamed, A. S., Noori, H. N. ve Anwar, G. (2021). Impact of service quality on the customer satisfaction: case study at online meeting platforms. International journal of Engineering, Business and Management, 5(2), 65-77. Erişim adresi: https://ssrn.com/abstract=3839031.

ASQ. (2011). American Society for Quality, Erişim adresi: http://www.asq.org, 26.08.2011.

Athanassopoulos, D. A. ve Iliakopoulos, A. (2003). Modeling customer satisfaction in telecommunications: assessing the effects of multiple transaction points on the perceived overall performance of the provider. Production and Operations Management, 12(2), 224-245. Erişim adresi: https://www.semanticscholar.org/.

Aydın, S., Özer, G. ve Arasıl, Ö. (2005). Customer loyalty and the effect of switching costs as a moderator variable: A case in the Turkish mobile phone market. Marketing Intelligence \& Planning, 23(1), 89-103.

Bucak, T. ve Turan, Ö. (2016). Restoranlarda hizmet kalitesinin misafir memnuniyetine etkisi: Çanakkale merkezinde bir araştrrma. International Journal of Social Science, 49 (1), 287-304. Erişim adresi: https://dergipark.org.tr/en/pub/ckuiibfd/issue/31317/371995.

Cheng, B. L., Mansori, S. ve Huei, C. T. (2014). The associations between service quality, corporate image, customer satisfaction, and loyalty: evidence from the Malaysian hotel industry. Journal of Hospitality Marketing \& Management, 23(3), 314-326.

Cronin, Jr., J. ve Taylor, S. (1992). Measuring service quality: a reexamination and extension. The Journal of Marketing, $56,55-68$.

Goi, Ch. L. (2009). A review of marketing mix: 4Ps or more? International Journal of Marketing Studies, 1(1), 2-14.

Grönroos, Ch. (1982). An applied service marketing theory. European Journal of Marketing, 16(7), 30-41.

DR. (2021). DataReportal. Erişim adresi: https://datareportal.com/reports/digital-2021-kyrgyzstan.

Iacobucci, D., Ostrom, A. ve Grayson, K. (1995). Distinguishing service quality and customer satisfaction: the voice of the customer. Journal of Consumer Psychology, 4(3), 277-303. doi:10.1207/s15327663jcp0403_04.

ISO. (2010). International Organization for Standardization. Erişim adresi: http://www.iso.org.

IWS. (2010-2021). Internet World Stats. Erişim adresi:https://www.internetworldstats.com/stats.htm.

Fox, K. F. A., Skorobogatykh, I. I. ve Saginova, O. V. (2005). The Soviet evolution of marketing thought, 19611991: from Marx to marketing. Marketing Theory, 5(3), 283-307.

Karahan, K. (2006). Hizmet pazarlaması. İstanbul: Beta Basım Yayım Dağıım.

KC MİA. (2010, 2020). KC Milli Iletişim Ajansı Raporlar, Erişim adresi: http://nas.gov.kg/dp/ezhegodnye-otchetyagenstva.

KC MiK. (2011, 2021). KC Milli İstatistik Komitesi, Erişim adresi: www.stat.kg.

Lee, H., Lee, Y. Ve Yoo, D. (2000). The determinants of perceived service quality and its relationship with satisfaction. Journal of Service Marketing, 14(3), 217-231. doi:10.1108/08876040010327220.

Lovelock, Ch. (1983). Classifying services to gain strategic marketing insights. Journal of Marketing, 47(3), 9-20. doi:10.2307/1251193.

Maksüdünov, A. (2007). KOBI’lerin pazarlama anlayışının belirlenmesine yönelik Kırgızistan'da bir araştırma. İçinde G. Gençyllmaz (Edt.), 4. KOBİ'ler ve Verimlilike Kongresi. (ss. 403-414). İstanbul, Türkiye: TC İstanbul Kültür Üniversitesi Yayınları.

McCarthy, E. J. (1964). Basic marketing. IL: Richard D. Irwin.

Nâsir, S. (2003). Türkiye’de GSM sektöründe müşteri memnuniyeti: Kullanıcıların operatör değiştirme eğilimlerinin saptanması. İçinde Ş. Akdoğan (Edt.). 8. Ulusal Pazarlama Kongresi (ss. 211-228). Kayseri, Türkiye: Kalkan Matbaacilik.

Nga, T. V., Chovancová, M. ve Tri, H. T. (2020). The impact of e-service quality on the customer satisfaction and consumer engagement behaviors toward luxury hotels. Journal of Quality Assurance in Hospitality \& Tourism, 21(5), 499-523.

Nimako, S. G. ve Azumah. K. (2009). An assessment and analysis of customer satisfaction with service delivery of mobile telecommunication networks in Ghana (Master Thesis). Lulea University of Technology, Sweden. 
Osman, Z. ve Sentosa, I. (2013). Mediating effect of customer satisfaction on service quality and customer loyalty relationship in Malaysian rural tourism. International Journal of Economics Business and Management Studies, 2(1), 2537. Erişim adresi: https://ssrn.com/abstract=2196815.

Özden, K. ve Oktay, K. (2009). Kırgızistan'da GSM operatörleri müşterilerinin fiyat algılamalarına yönelik bir araştırma. Sosyoekonomi, 10(10), 159-175. Erişim adresi: https://dergipark.org.tr/en/download/articlefile/197656.

Parasuraman, A., Berry, L. ve Zeithaml, V. A. (1988). SERVQUAL: multiple-item scale for measuring consumer perceptions of service quality. Journal of Retailing, 64(1), 12-40. Erişim adresi: https://www.semanticscholar.org/.

Ping-Lung, H., Bruce, C. Y. ve Ching-Chin, Ch. (2019). The influence of service quality on customer satisfaction and loyalty in B2B technology service industry. Total Quality Management \& Business Excellence, 30(13-14), 1449-1465.

Polat, D. D. C. ve Maksüdünov, Y. D. D. A. (2015). Mobil telefon tercihinde etki faktörleri-Kırgızistan'daki üniversite öğrencileri üzerine bir çalışma. Manisa Celal Bayar Üniversitesi Sosyal Bilimler Dergisi, 13(2), 187-208.

Rafiq, M. ve Ahmed, P. K. (1995). Using the 7Ps as a generic marketing mix: An exploratory survey of UK and European marketing academics. Marketing Intelligence \& Planning, (13)9, 4-15.

Rust, R. T., Zahorik, A. J. ve Keiningham, T.L. (1996). Service marketing. New York: Harper Perennial.

Sasono, I., Jubaedi, A. D., Novitasari, D., Wiyono, N., Riyanto, R., Oktabrianto, O., ... Waruwu, H. (2021). The impact of e-service quality and satisfaction on customer loyalty: empirical evidence from internet banking users in Indonesia. The Journal of Asian Finance, Economics and Business, 8(4), 465-473.

Solimun, S. ve Fernandes, A.A.R. (2018). The mediation effect of customer satisfaction in the relationship between service quality, service orientation, and marketing mix strategy to customer loyalty. Journal of Management Development, 37(1), 76-87.

Tayyar, N. ve Dilşeker, F. (2012). Devlet ve vakıf üniversitelerinde hizmet kalitesi ve imajın öğrenci memnuniyetine etkisi. Muğla Üniversitesi Sosyal Bilimler Enstitüsü Dergisi, 28, 184-204. Erişim adresi: https://dergipark.org.tr/tr/pub/musbed/issue/23512/250505.

Weng-Kun, L., Yueh-Shian, L. ve Li-Mei, H. (2017). The interrelationships among service quality, customer satisfaction, and customer loyalty: examination of the fast-food industry. Journal of Foodservice Business Research, 20(2), 146-162.

Woo, K-Sh. K. ve Fock, H. Y. (1999). Customer satisfaction in the Hong Kong mobile phone industry. The Service Industries Journal, 19(3), 162-174.

World Bank. (2021). World Development Indicators, Erişim adresi: https://databank.worldbank.org/source/worlddevelopment-indicators.

Zhang, X. ve Feng, Y. (2009). The impact of customer relationship marketing tactics on customer loyalty within Swedish mobile telecommunication industry (Master Thesis), Halmstad University, Halmstand.

Zeithaml, V. A. ve Bitner, M. J. (2000). Service marketing: integrating customer focus across the firm. Boston: Irwin McGrawHill.

Аристов, О. В. (2009). Управление качеством. Москва: Инфра - М./ Aristov, О.В. (2009). Upravleniye kachestvom. Moskva: Infra-M.

Аавлок, К. (2005). Маркетинг услуг: Персонал, технологии, стратегии. Москва: Вильямс. / Lovelock, Ch. (2005). Marketing uslug: personal, tehnologii, strategii. Moskva: Viliyams.

Миронова Н. В. (2003). Маркетинг различных типов услуг. Маркетинг в России и за рубежсм, 4. Erişim adresi: http://www.mavriz.ru/articles/2003/4/31.html. /Mironova, N. V. (2003). Marketing v razlichnih tipov uslug. Marketing v Rossii i za rubejom, 4. Erişim adresi: http://www.mavriz.ru/articles/2003/4/31.html.

Новаторов, Э. (2008). Сравнительный анализ теорий маркетинга услуг. Вестник СпбГУ, 8(2), 40-55. Erişim adresi: http://vestnikmanagement.pu.ru/archive/pdf/350.pdf. / Novatorov, E. (2008). Sravnitelniy analiz teoriy marketinga uslug. Vestnik SpbGU, 8(2), 40-55. Erişim adresi: http://vestnikmanagement.pu.ru/archive/pdf/350.pdf.

Токсобаева, Б.А. ve Токсобаев, Б.Т. (2007). Система менедмента качества. Бишкек. /Toksobaeva, В.А. ve Toksobaeva, B.T. (2007). Sistema menedjmenta kachestva. Bishkek.

Хаксевер, Ж., Рендер, Б., Рассец, Р.С. vе Мердик, Р. Г. (2002). Управление и организачия в сфере услуг. (2-е международное издание). Питер. / Haksever, J., Render, B., Rassel, R.S. ve Merdik, R.G. (2002). Upravleniye $i$ organizatsiya $v$ sfere uslug. (2-e mejdunarodnoye izdaniye). Piter.

\section{EXTENDED ABSTRACT}

Technologic developments have led to rapid changes in the communication sector all over the world. Today, the internet and mobile phones increase our communication opportunities and make our lives easier. While there were around 4.5 billion mobile phone users on a global scale and 5,3 million in Kyrgyzstan in 2010, these indicators are seen to reach 8.0 billion and 7.3 million, respectively, by 2021 . Despite the increase in the quantitative indicators of the service sector in the country, it is noteworthy that there are serious gaps in service quality and marketing practices. Therefore, the main purpose of this study is to evaluate service marketing and quality management practices in the GSM sector in Kyrgyzstan. 
In the information era, every business is seen as a service business, and every manager is seen as a service manager. Market conditions make impossible to sell a tangible good to the consumer without additional services or, on the contrary, without supporting a service with tangible products. Service industry in a country is accepted as a development indicator of the country. Academic studies show that service industry is the leading sector in many economies and the theoretical basis on management of the industry is constantly being developed and supported by new researches. According to the literature on service marketing and service quality, there is a strong and positive relationship between these two variables. And recent studies are focusing on marketing and quality of technological services and eservices. Studies show, that service quality should be defined by consumers. The consumer at an estimation of services pays attention to such factors such as physical environment, reliability, empathy etc. Efficient management of these factors demands application of the modern concept of marketing at the enterprises. In other words, it can be concluded that the service quality is the result of marketing performance of service operators.

Kyrgyzstan declared its independence in 1991 after the collapse of the Soviet Union and started the process of transition to the market economic system in order to be integrated into the world economy. During this transition period Kyrgyzstan is exposed to many new concepts such as private property, entrepreneurship, competition and marketing, which are important elements of the market economy, for the first time. Since domestic entrepreneurs and managers in the private sector didn't have sufficient knowledge and experience in customer-oriented marketing approach, businesses continued to apply production and sales-oriented marketing concepts. On the other hand, since the understanding of marketing in the Kyrgyzstan market at that time and the environment requiring marketing were not yet formed, even businesses established with foreign capital did not consciously apply the customer-oriented marketing approach.

The GSM sector follows a more active marketing policy than other service sub sectors in Kyrgyzstan due to the characteristics of the sector, the conditions of competition and the experience of the business owners and managers. However, when we evaluate the industry practices in terms of marketing mix components, it is seen that the companies' activities are concentrated on some elements such as price, promotion and physical evidence. Compared to 2010, it is seen that there are some developments regarding service marketing and thus service quality in 2021. If the service quality depends on the marketing performance that the customers expect and perceive, how successful are the existing businesses in this regard? These issues need to be supported by field studies.

In this direction, results of this paper can offer some crucial insights in terms of managerial and public policy implications. Relevant state institutions should continue their efforts on the implementation of national and international quality standards by enterprises, the creation of free competition conditions in the sector, and the development of the legal infrastructure for the protection of consumer rights. GSM enterprises should be encouraged to adopt and implement quality standards. GSM companies need to transform their corporate culture from product oriented approach to customer oriented. Decisions regarding service quality, marketing and all other business activities should be based on sound information from marketing research. In other words, research should be given importance and research expenses should be considered as an investment. Integrated marketing should be adapted by GSM companies as a key to high quality services and sustainable development.

Problems related to service marketing and service quality are not unique to the GSM sector in Kyrgyzstan. As it is known, problems related to service quality and customer satisfaction hinder the development of many public and private sector institutions and organizations in our country. Modern understanding of marketing and quality isn't only limited to a product or a business, it is crucial in terms of quality in the society. 